\title{
Histological Study of the Effect of Bioactive Glass on Tibial Bone Repair in Rats
}

\author{
Gamal Abdel Salam ${ }^{1}$, Ali M. Ali ${ }^{1}$, Osama F. Ahmed ${ }^{1}$, Ibrahim S. Ali ${ }^{2,}$ * \\ ${ }^{1}$ Anatomy Department, Benha Faculty of Medicine, Benha University, Benha City, Egypt \\ ${ }^{2}$ Faculty of Public Health and Health Informatics, Umm al- Qura University, Makah City, Saudi Arabia \\ Email address: \\ Ibrahim_shoub@hotmail.com (Ibrahim S. Ali), Drgamal19@yahoo.com (G. A. Salam)
}

\section{To cite this article:}

Gamal Abdel Salam, Ali M. Ali, Osama F. Ahmed, Ibrahim S. Ali. Histological Study of the Effect of Bioactive Glass on Tibial Bone Repair in Rats. International Journal of Clinical and Developmental Anatomy. Vol. 1, No. 2, 2015, pp. 13-21. doi: 10.11648/j.ijcda.20150102.11

\begin{abstract}
The main goal of this study was to histologically evaluate the healing of surgically created defects on the tibiae of adult rats after implantation of bioactive glass. Twenty adult Wistar rats (body weight of $300 \mathrm{~g}$ ) were divided into two groups: bioglass treated group $(n=10)$ and control group $(n=10)$. Unicortical bone defects with 3-mm diameter were performed in both tibiae of the animals and filled with bioglass particles. The rats were then sacrificed at 14, 30, 60 and 90 days, and the tissues were prepared for histological processing, sectioning, and staining with hematoxylin and eosin, as well as Mallory trichrome, and analyzed under light microscope. Within 7-14 days, both groups presented connective tissue septa with new bone formation, more intense in bioglass treated group. In the subsequent periods (30,60 and 90 days), these groups presented more mature bone tissue around the glass particles. Bone trabeculae formed in all experimental periods were juxtaposed to the glass particles. It can be concluded that bioglass materials promoted bone formation over the entire extension of the defect, independently of the size of the granules, thus confirming their biological osteoconductive property.
\end{abstract}

Keywords: Bioglass, Albino Rat, Tibial Repair, Bone Healing

\section{Introduction}

Millions of fractures occur every year worldwide, with 6.2 million of them being reported per year in the United States (1). Among those, 5-10\% show delayed healing; many persist for more than 9 months, and thus are termed nonunion fractures. Multiple factors can impair fracture consolidation, including bone loss caused by diseases, trauma, or tumor resection. Hence, there remains a need to learn more about the biology of fracture healing as well as to develop strategies for ensuring normal repair of the skeleton (2).

Bone graft substitutes can be broadly divided into two main groups; biological and synthetic materials. Biological substitutes broadly include allografts or xenografts, and also corals (3), natural polymers - collagen like (4) or demineralized bone matrix (DBM) (5). Allografts/xenografts are still related with risk of disease transmission or immune rejection, as well as with reduced biological properties following sterilization and storage, (6), and thus have limited usage. Synthetic graft substitutes include porous metals, (7), bioactive glasses, (8), glass-ceramics, (9), synthetic polymers (e.g. synthetic hydroxyapatite), (10), and calcium phosphates/sulphates (11). Such materials pose an ever expanding portfolio of indications and have attracted significant scientific and clinical interest.

Calcium-phosphate ceramics, such as hydroxyapatite, have been used because their chemical composition is closely related to that of the mineral phase of bone (12). These ceramics are adequately biocompatible, and do not induce adverse local tissue reactions, immunogenicity, or systemic toxicity. Furthermore, because this material is osteoconductive, it acts as a support for new bone formation within the pore sites, which are deliberately generated in the structure, (13).

Unexpected results due to the use of the materials mentioned above have directed technological advances to recent studies with some bio-active materials to be used as bone substitutes, in several kinds of defects in the field of Dentistry. Bioactive glass has shown the ability to help bone regeneration and clinical insertion gain, with better results than other materials available, $(14,15,16 \& 18)$. This material has also demonstrated osteoconductive and osteopromotive abilities in the biocompatible interface for osseous migration, and a bioactive surface colonized by 
osteogenic cells free in the surgical wound (19).

The use of Bioglass particles promotes a much faster proliferation of new bone tissue, comparable to that occurring after the use of autogenous bone graft; furthermore, the combination of Bioglass granules and autogenous bone results in more bone growth when compared to the autogenous material, (20). Bioglasses inducing active biomineralization for bone regeneration have been a high demand in the development of clinical regenerative medicine. Recent development of biomaterials in the field of tissue regeneration includes bioactivity inducing cell adhesion, and differentiation to achieve early healing efficacy (21).

One of the most common and studied bioactive glasses is Bioglass 45S5, which has been known as the bioactive glass with the highest bioactivity index. It was first introduced in the early 1970 s by Hench (22) and since then, it has been used in many clinical applications, including ridge preservation, sinus augmentation, and the repair of periodontal bone defects (23). It is a silica-based meltderived glass characterized by a $\mathrm{SiO} 2$ content of less than $60 \%$, a high $\mathrm{Na} 2 \mathrm{O}$ and $\mathrm{CaO}$ content, and a high $\mathrm{CaO}$ : $\mathrm{P} 2 \mathrm{O} 5$ ratio. Bioglass 45S5has been shown to stimulate in vitro osteogenesis inducing proliferation and differentiation of human fibroblasts and osteoblasts $(24,25 \& 26)$.

A novel fully-crystallized bioactive glass-ceramic of the quaternary $\mathrm{P} 2 \mathrm{O} 5-\mathrm{Na} 2 \mathrm{O}-\mathrm{CaO}-\mathrm{SiO} 2$ system has been developed (Biosilicate, patent application WO 2004/ 074199). Therefore, full crystallization of the material may lead to enhanced mechanical properties of the bulk material or less sharp and abrasive particles when the material is milled to a powder. The Biosilicate has presented a stimulatory effect on bone cell metabolism. Comparing the growth of osteogenic cells on Biosilicate and Bioglass 45S5 disks for a period of up to 17 days, they found that, although no significant differences were detected in terms of protein content and alkaline phosphatase activity at days 11 and 17, Biosilicate supported significantly larger areas of calcified matrix at day 17. Results indicate that full crystallization of bioactive glasses in a range of compositions of the system P2O5$\mathrm{Na} 2 \mathrm{O}-\mathrm{CaO}-\mathrm{SiO} 2$ may promote enhancement of in vitro bone-like tissue formation in an osteogenic cell culture system, (27).

Notwithstanding the positive effects of Biosilicate on bone cell proliferation, studies investigating its effects on bone healing are fairly limited in the literature. To the best of our knowledge, there is one study demonstrating in vitro osteogenesis on a highly bioactive glass-ceramic. It is important to emphasize that in vitro studies do not consider the complex homeostatic situation that occurs in vivo. In order to progress our understanding of the physiological processes of the Biosilicate_on fracture consolidation, the goal of Ribeiro and Masumoto (28) study was to examine the mechanical and histological characteristics of bone defects filled with two different particle sizes of biosilicate materials (180-212 and 300-355 $\mathrm{lm}$ mean size) and to compare these characteristics to those obtained with a Bioglass_material of similar particle sizes. An additional control group, that remained empty, was included. Recently, we have applied this methodology with success in rats exposed to laser, treated or not with anti-inflammatory drugs (29).

\section{Material and Methods}

In the present study, 20 male rats (Rattus norvegicus, Albinus, Wistar) weighing $300 \mathrm{~g}$ were used, which were fed a solid diet before and during the experimental period and received water ad libitum. They were classified into two groups; control group (10 rats), and bioglass treated group (10 rats).

\subsection{Bone Substitutes}

\subsubsection{Preparation of Bioactive Silicate Glass}

All chemicals used in preparation of glasses such as finegrained Quartz $\left(\mathrm{SiO}_{2}\right)$, calcium carbonate $\left(\mathrm{CaCO}_{3}\right)$, sodium carbonate $\left(\mathrm{Na}_{2} \mathrm{CO}_{3}\right)$, and ammonium dihydrogen orthophosphate $\left(\mathrm{NH}_{4} \mathrm{H}_{2} \mathrm{PO}_{4}\right)$ are selected from high pure chemicals. All the chemicals were of analytical grade and were used without further purification. Quartz was used for silica $\left(\mathrm{SiO}_{2}\right)$. Lime $(\mathrm{CaO})$ and soda $\left(\mathrm{Na}_{2} \mathrm{O}\right)$ were introduced in the form of their respective anhydrous carbonates. Phosphorus pentoxide $\left(\mathrm{P}_{2} \mathrm{O}_{5}\right)$ was added in the form of ammonium dihydrogen orthophosphate $\left(\mathrm{NH}_{4} \mathrm{H}_{2} \mathrm{PO}_{4}\right)$ and finally $\mathrm{ZnO}$ was added. The batches were weighed out and then melted in an $\mathrm{Pt}-2 \% \mathrm{Rh}$ crucible using electric furnace at $1500{ }^{\circ} \mathrm{C}$ for $2 \mathrm{~h}$ and the melts were rotated two times to achieve homogeneity. Upon complete melting, the glasses were cast in a preheated stainless steel rectangular mould of the dimensions of $1 \mathrm{~cm} \mathrm{x} 4 \mathrm{~cm} \mathrm{x} 1 \mathrm{~cm}$ preheated to about 250 ${ }^{\circ} \mathrm{C}$. The glass samples were transferred to an annealing muffle furnace adjusted at $740{ }^{\circ} \mathrm{C}$ and the muffle was left to cool slowly to room temperature. The samples were polished with 600-grit silicon carbide until their thickness became $1 \mathrm{~mm}$ and then polished with 1200-d 2500-grit of silicon carbide and cerium oxide ( table1).

Table 1. Bioactive Silicate Glass Sample Composition.

\begin{tabular}{lllll}
\hline $\mathrm{SiO}_{2}$ & $\mathrm{Na}_{2} \mathrm{O}$ & $\mathrm{CaO}$ & $\mathbf{P}_{2} \mathbf{O}_{5}$ & $\mathbf{Z n O}$ \\
$\mathbf{W t} \%$ & $\mathbf{W t} \%$ & $\mathbf{W t} \%$ & $\mathbf{W t} \%$ & $\mathbf{W t} \%$ \\
\hline 45 & 22.5 & 23.5 & 6 & 3 \\
\hline
\end{tabular}

\subsubsection{Heat-treatment (Conversion to Glass-ceramic)}

The glass sample was thermally heated in two-steps regime at the mentioned temperatures. Glass was heated slowly to the first nucleation temperature $\left(550{ }^{0} \mathrm{C}\right)$ for the formation of sufficient nuclei sites and after holding for $3 \mathrm{~h}$, it was then further heated or raised to reach the second chosen crystal growth temperature $\left(763^{\circ} \mathrm{C}\right)$, and after a second hold for $3 \mathrm{~h}$, the specimen was left to cool inside room temperature at a rate of $20{ }^{0} \mathrm{C} / \mathrm{h}$., (22).

\subsection{Surgical Procedure}

Before surgery, the animals were weighed for a correct calculation of the anesthetic dosage. General anesthesia was used with intramuscular application of a sedative solution - 
hydrochloride 2-(2.6 xylidine)-5.6-dyhidro-4H-1.3- thiazine, and ketamine anesthetic $1.0 \mathrm{~g}$, in the proportion of $1: 0.5 \mathrm{ml}$ in the $0.1 \mathrm{ml} / 100 \mathrm{~g}$ of body weight.

After trichotomy and asepsis of the surgical field with iodine, the lateral and superior aspects of the tibiae in both posterior paws were exposed with a $1.5-\mathrm{cm}$ long incision, using a 15 interchangeable blade, on a Bard-Parker scalpel, photographed grossly, (Fig.6). Tissue separation was performed with periosteum elevators and a Molt elevator, so as to obtain a mucoperiosteal flap to expose the bone tissue and allow free access to create osseous defects. In both paws (right in some and left sided in others), a monocortical bone defect measuring $3 \mathrm{~mm}$ in diameter was prepared with aseptic electric engine, using a 1/16 reduction, straight tip, trephine drills, at a speed of $1500 \mathrm{rpm}$, under copious irrigation with $0.9 \%$ sterile saline solution throughout the bone manipulation. Before placing bone filling glass materials, the bone cavities were irrigated with antibiotic.

Bioactive glass granules were placed to fill the bone defect The materials were prepared just before being used, $0.9 \%$ sterile saline solution was added to the flasks, sterilized with gamma rays provided by the manufacturer, until a paste-like texture was obtained. The flaps were closed with 4-0 silk intermittent sutures, and deeper planes were closed with absorbable Vicryl 4-0 suture. Immediately after the surgical procedure, all animals received intramuscular application of antibiotics and anti-inflammatory drugs, in the dosage of $0.2 \mathrm{ml} / \mathrm{kg}$ of body weight.

The site of operation was seen via x-ray in fig.8. However, the site of healing was evident in fig.7.

\subsection{Histological Study}

The animals were sacrificed with an overdose of anesthetic at 14, 30, 60 and 90 days after the surgical procedures. After removal of soft tissues, bone fragments including the implanted material were obtained and fixed in a $10 \%$ formalin solution for at least 48 hours. Decalcification was accomplished in $20 \%$ sodium citrate and $50 \%$ formic acid solution, 1:1. The decalcified samples were embedded in paraffin and $6-\mu \mathrm{m}$ thick semi-serial sections were obtained and stained with hematoxylin-eosin and Mallory trichrome for light microscopy analysis (30).

\section{Results}

After 14 days, the spaces filled by particles of implanted materials showed varying sizes and were surrounded by granulation tissue and thin woven bone trabeculae. Some of the trabeculae were lamellar and were associated with marrow tissue. That aspect could be seen up to the center of the surgical defect, extending inside the marrow space. Some particle spaces were divided by thin bone septa on the inside, dividing them into smaller portions. New bone formation was observed next to the defect borders, with newly formed trabeculae covered by osteoblasts, both facing the periosteum and inside the medullary channel (fig.1).

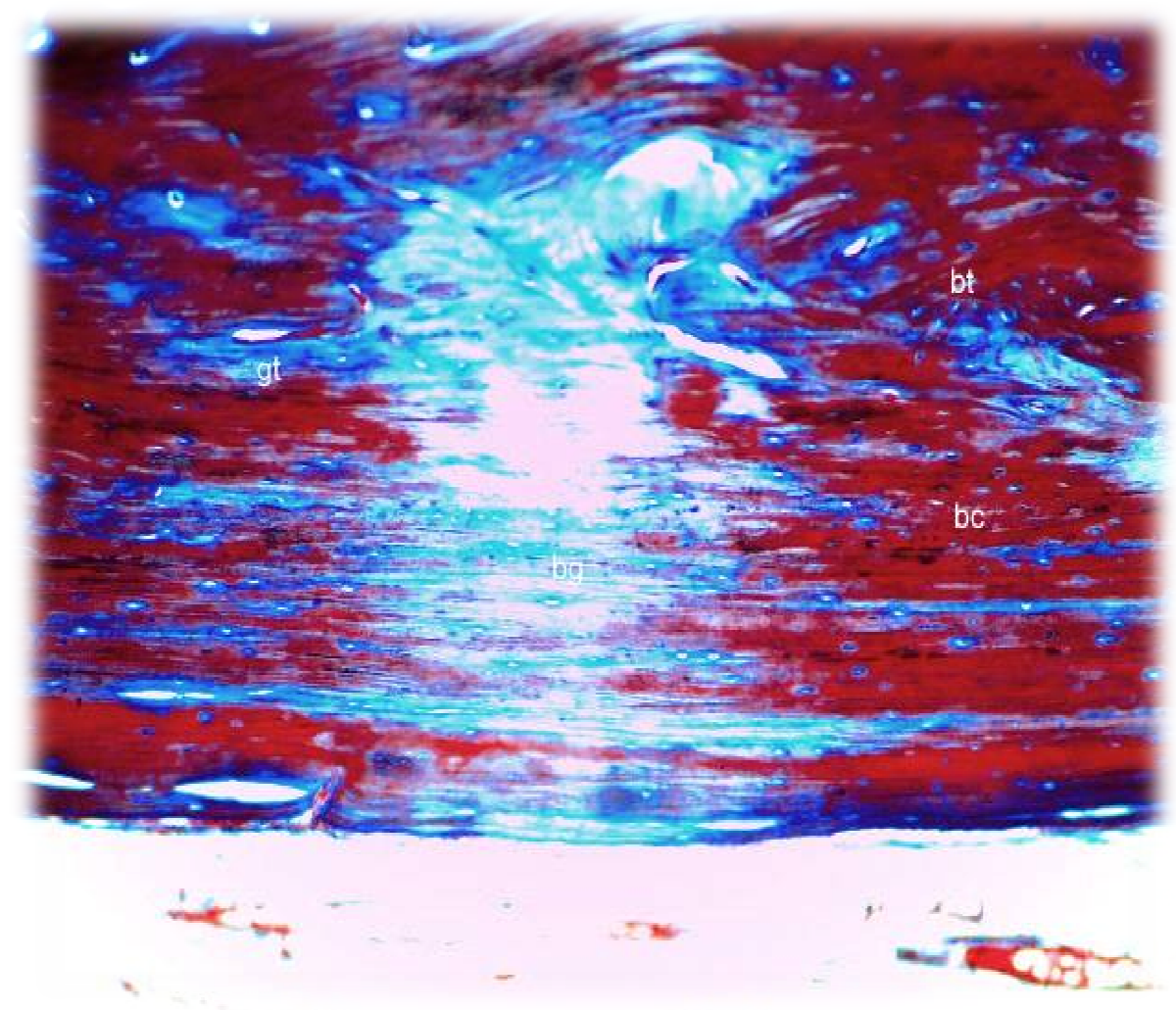

Fig. 1. A photomicrograph of the rat tibia, 14 days after operation (bioglass treated) showing; spaces filled with bioglass particles (bg) surrounded by granulation tissues (gt). There are many bone trabeculae (bt) with newly formed bone cells (bc). Masson trichrome X 200. 
After 30 days, bone trabeculae surrounding the spaces taken up by implanted particles were more mature and interspersed with bone marrow. On the surgical defect margins, basophilic lines could be observed inside. Mild signs of excavated internal pouches of granules could be seen, which would function as sites to stimulate new bone formation (fig.2).

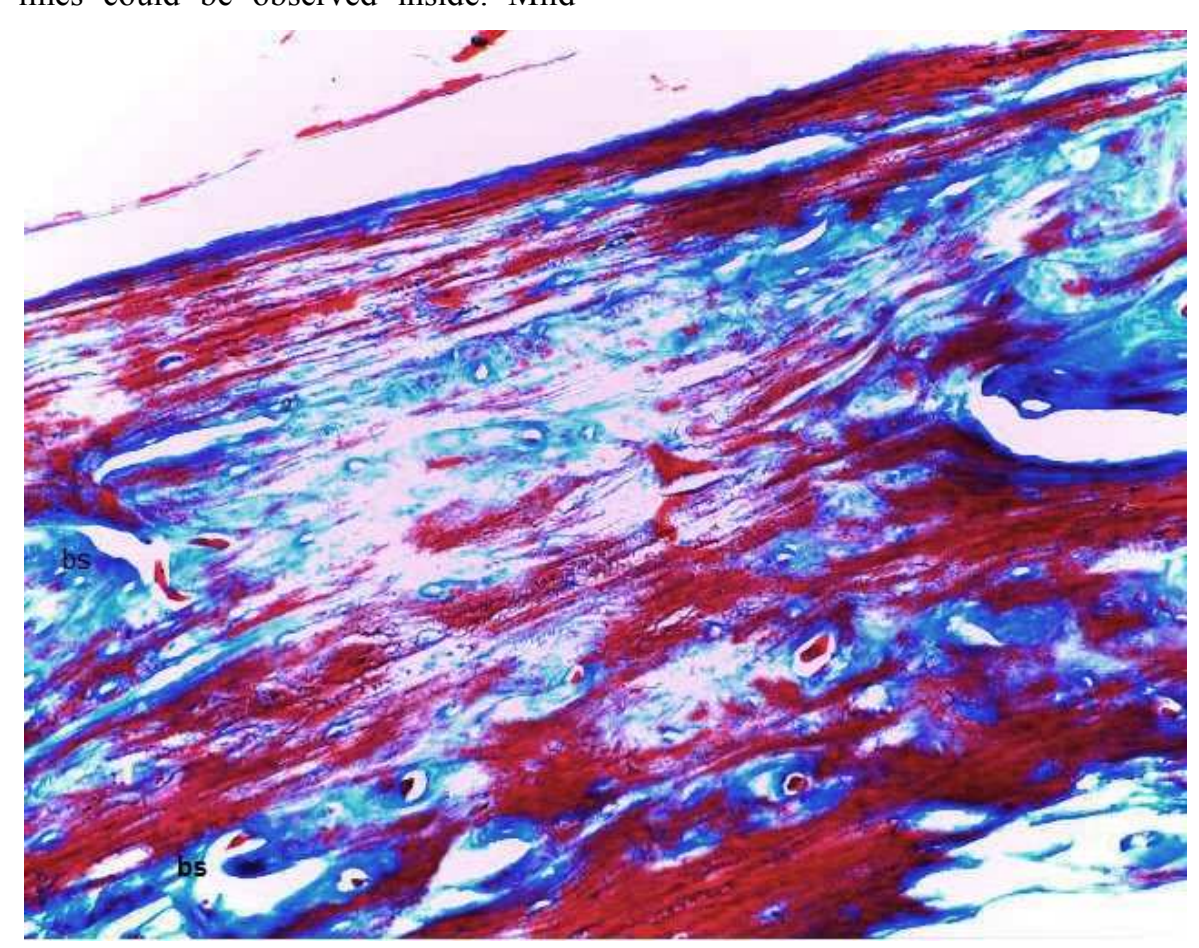

Fig. 2. A photomicrograph of the rat tibia, 30 days after operation (bioglass treated) showing; bone trabeculae surrounding the spaces taken up by glass particles. Bone septa are found inside the spaces (bs) with newly formed bones cells. (Masson trichrome, X 200).

After 60 days, bone trabeculae surrounding the spaces of the particles were thicker and more mature than in the previous stages, which showed signs of remodeling, as occurred on the surgical defect borders, and were interspersed with bone marrow. In some spaces, bone tissue formed in their excavations was observed in addition to thin bone septa. (Figure 3).
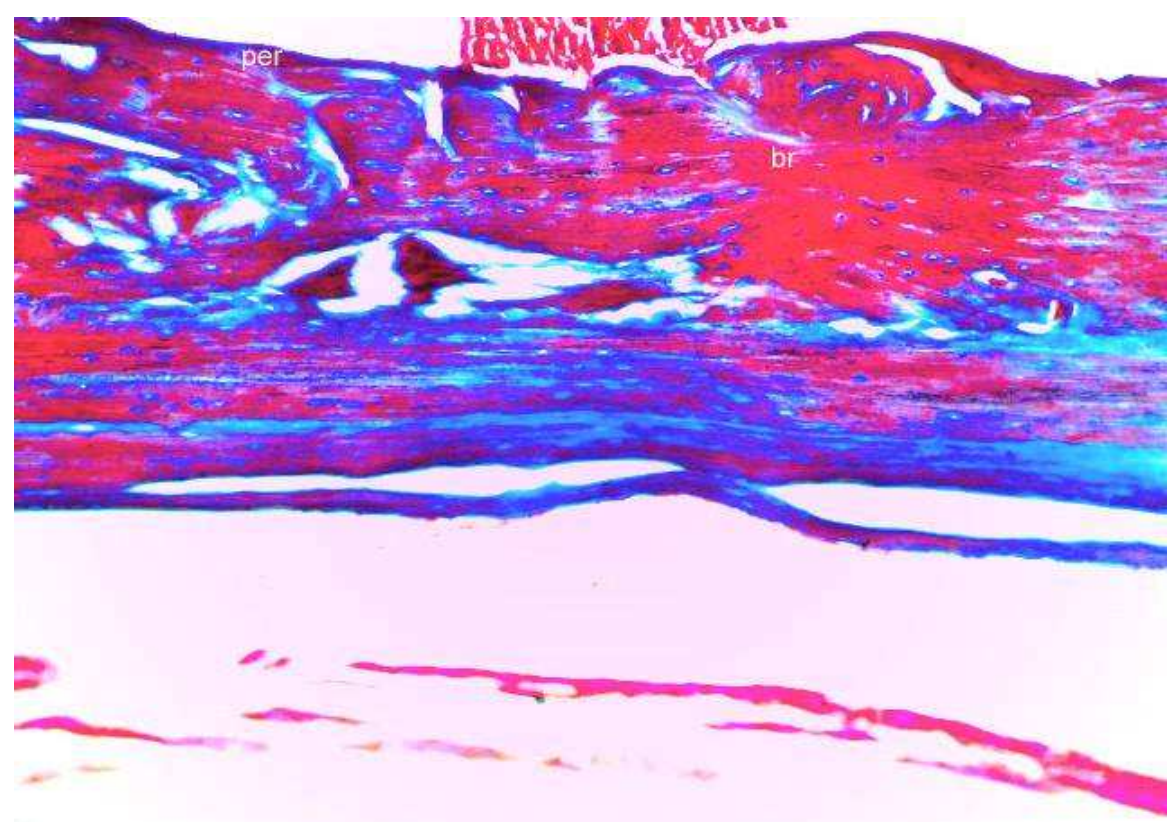

Fig. 3. A photomicrograph of the rat tibia, 60 days after operation (bioglass treated) showing; Thick lamellar bone surrounding the spaces taken up by bioglass with a picture of bone remolding (br). Well repaired periosteal layer can be seen (per). Masson trichrome X 200. 
After 90 days, a picture of many bone trabeculae with well-developed bone cells, simulating normal (fig.4). In fig.5

a normal intact periosteal layer, with well-defined normal bone cells can be seen.

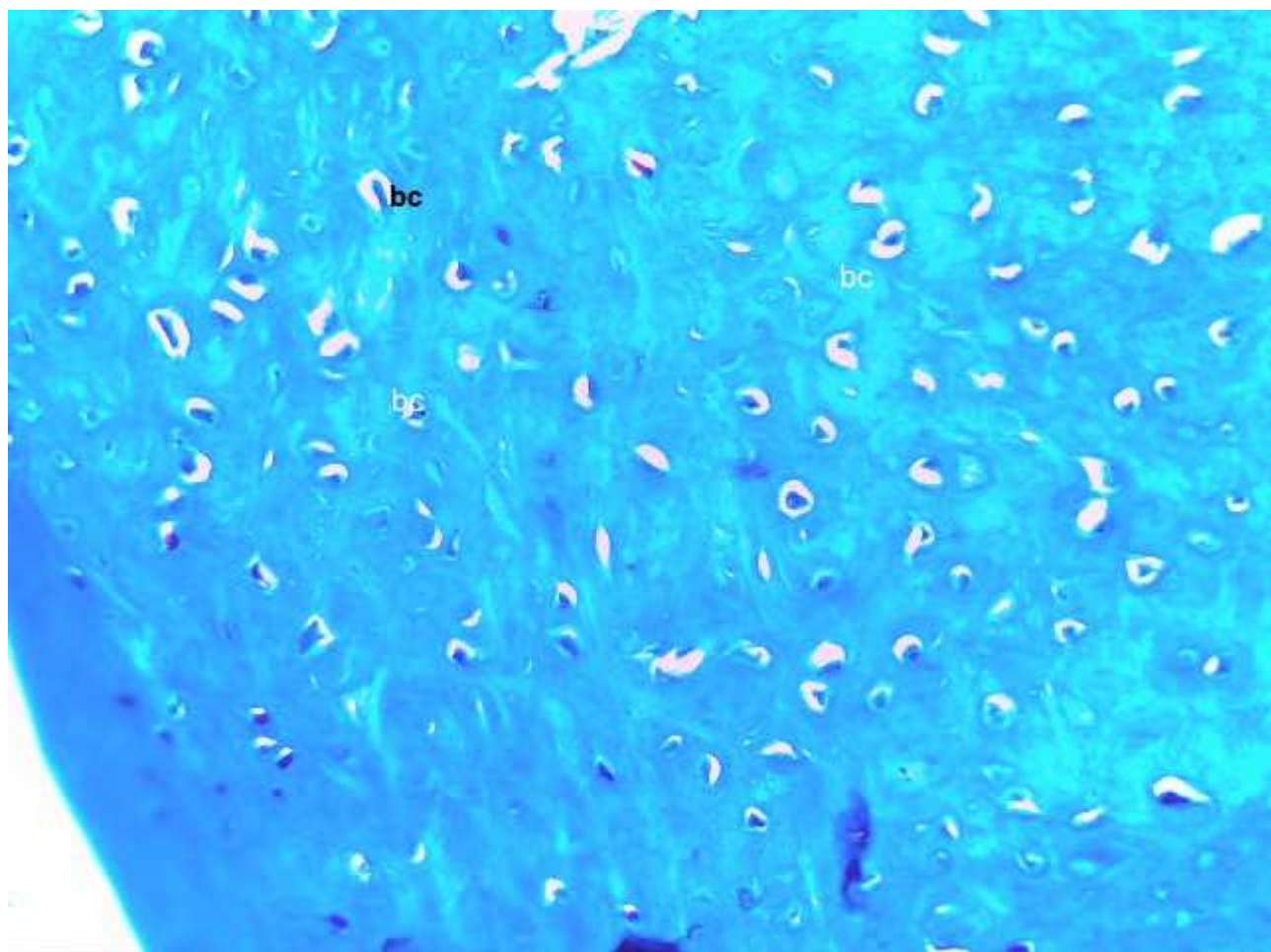

Fig. 4. A photomicrograph of the rat tibia, 90 days after operation (bioglass treated) showing; many bone cells (bc) filling most of the spaces taken up by the bioglass. Masson trichrome X 200.

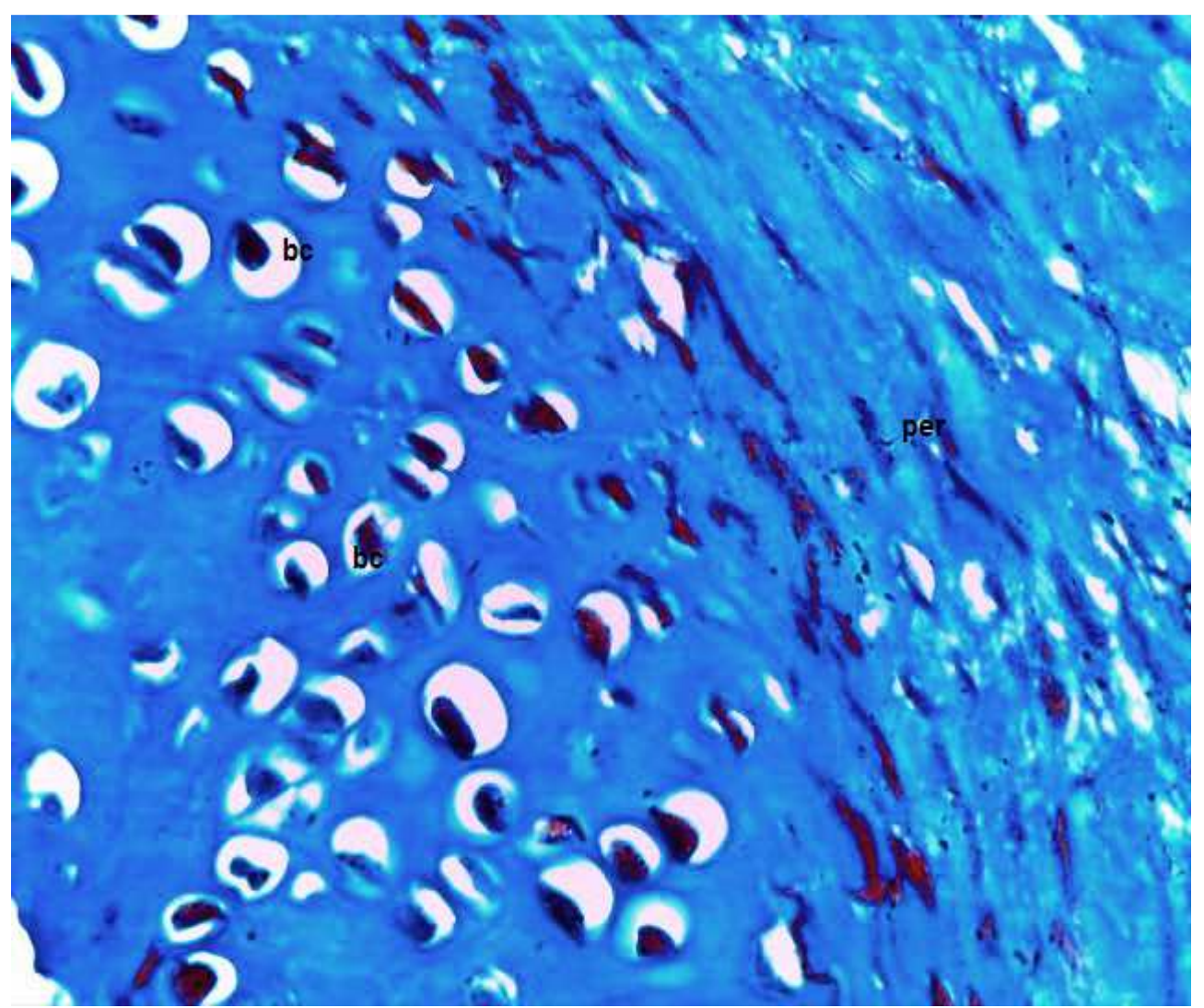

Fig. 5. A photomicrograph of the normal rat tibia, showing normal intact periosteal layer (per), with well-defined normal bone cells (bc). Masson Trichrome X 400 . 


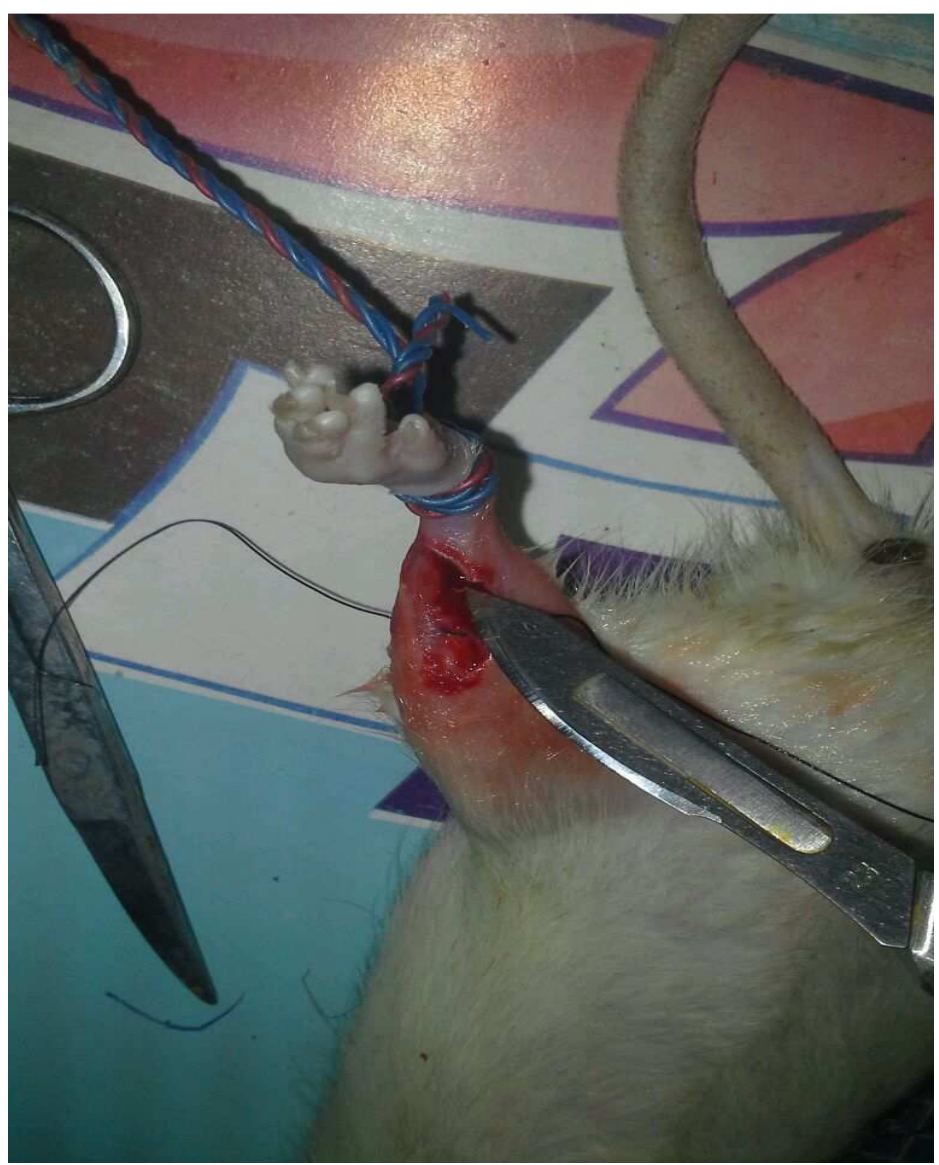

Fig. 6. A photograph of the rat operated on for exposure and making a bone defect in rat tibia.

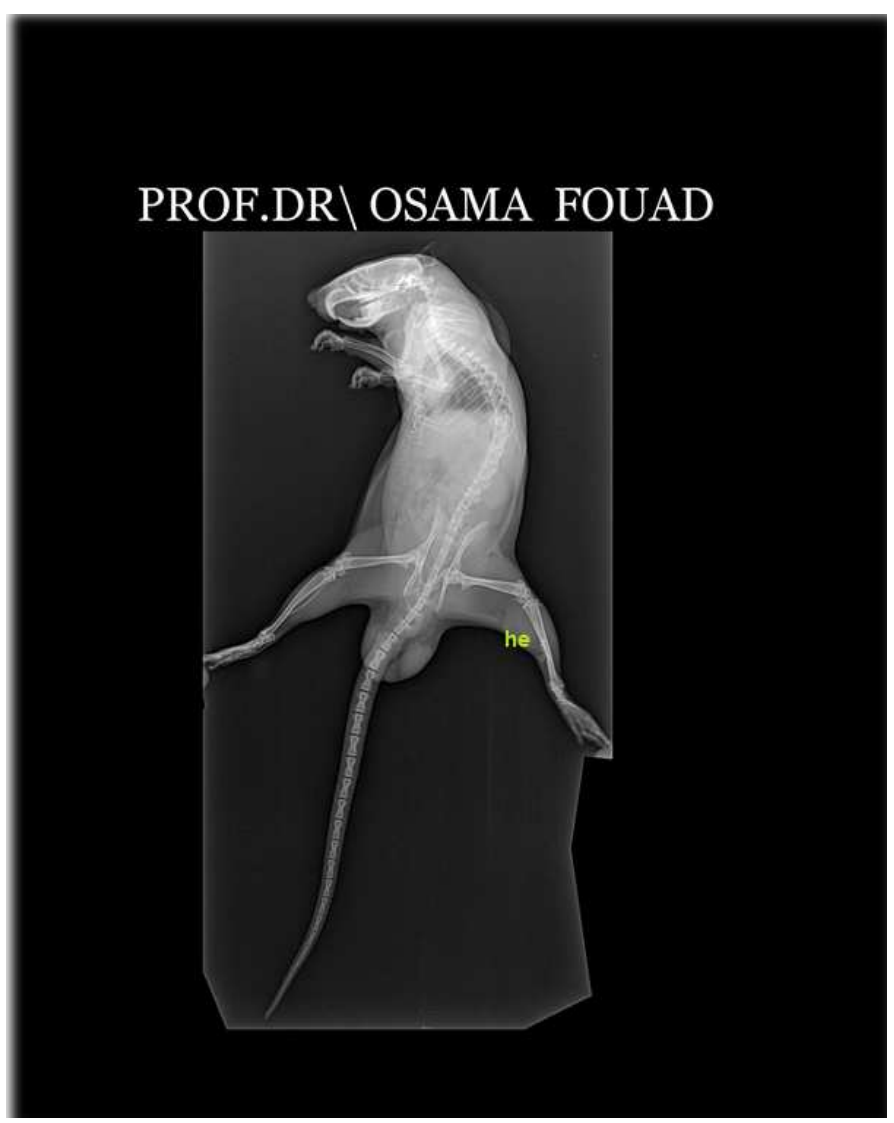

Fig. 7. An x-ray photo of the rat showing, the site of healing on the rat left tibia (he). 


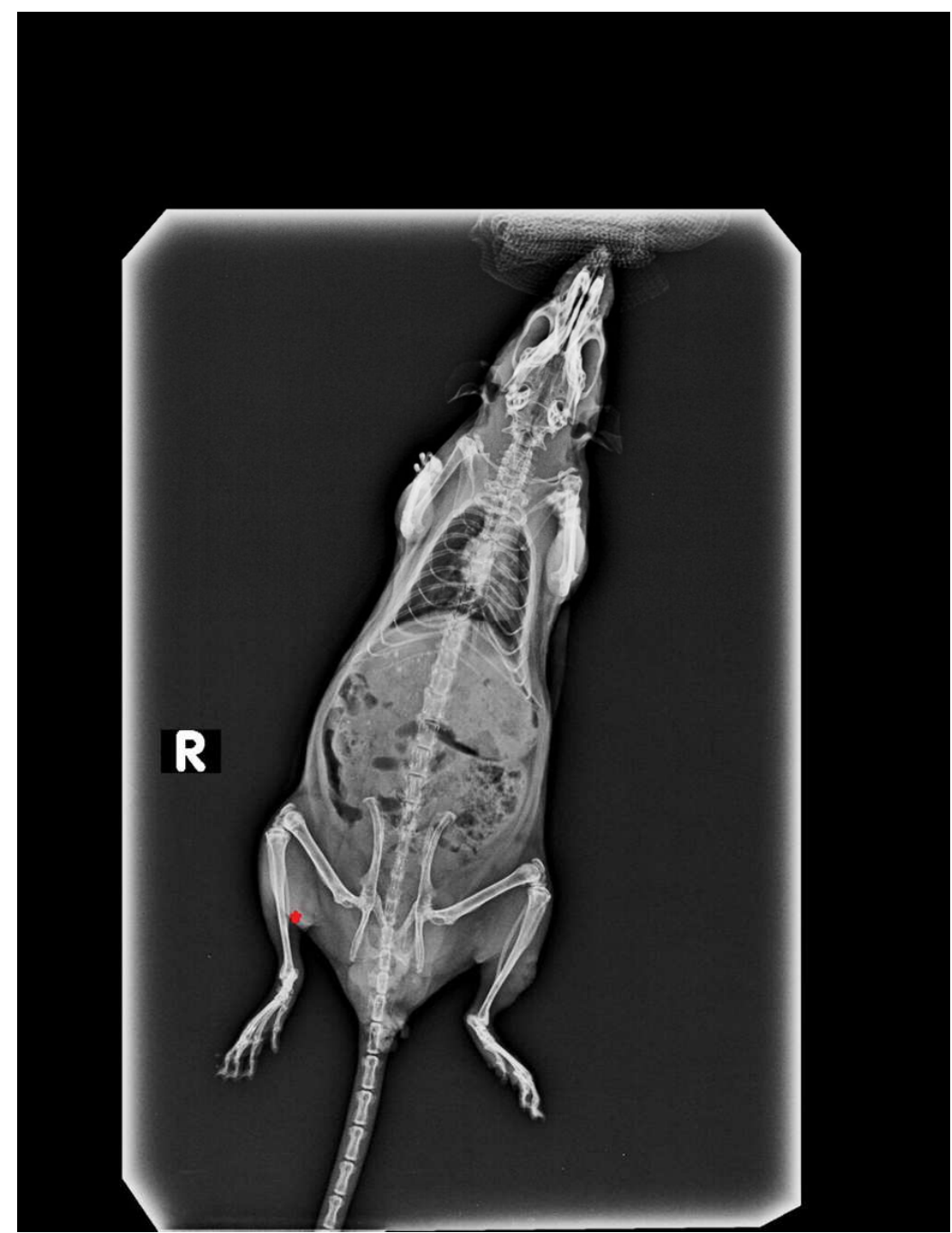

Fig. 8. Photograph of an X-ray of the rat to show the site of operation, (red star).

\section{Discussion}

There is a need for synthetic bone graft substitutes to repair large bone defects resulting from trauma, malignancy and congenital diseases. Bioactive glass has attractive properties as a scaffold material but factors that influence its ability to regenerate bone in vivo are not well understood (31).

Bone defects may occur because of various systemic and dental disorders. The nature of bone consists of polymer composites and calcium phosphate nanoparticles. Different materials have been introduced as bone substitutes. Using allografts may be more favorable in some cases, but because of possible immune reaction and infection transmission their application is limited. Therefore, surgeons and dentists have considered synthetic bone substitutes and bone tissue engineering as alternatives (32).

After implantation of any biomaterial, the host tissue will inevitably be traumatized by the implantation procedure (33). An inflammatory response triggered by BG-CH (bioglasschitosan) particles was observed after 1 week of bone implantation. 60 days after surgery, no systemic or regional surgical complications were seen. Under optical microscopy, it is clear that BG-CH architecture allowed for tissue ingrowth and subsequent migration into and through the matrix. BG-CH increased the bone contact perimeter and the new formed bone became mature more quickly. The present study revealed that the fully crystallized bioglass has good bone-forming and bone-bonding properties which were in line with Wiley, 2011 (34).

Bioglasses inducing active biomineralization for bone regeneration have been a high demand in the development of clinical regenerative medicine. Recent development of biomaterials in the field of tissue regeneration includes bioactivity inducing cell adhesion, and differentiation to achieve early healing. This was evident in our present study and the work of, Hench et al, 2004 (21).

In our study, after 14 days, the spaces filled by particles of implanted materials showed varying sizes and were surrounded by granulation tissue and thin woven bone trabeculae. Some of the trabeculae were lamellar and were associated with marrow tissue. That aspect could be seen up to the center of the surgical defect, extending inside the marrow space. It is in current with Oonishi et al. 1997 (20), 
who showed full restoration of the implantation site filled with Bioglass 45S5 within 2 weeks. The same results were found by Wheleer, et al., 2001 (35).

In the present study After 30 days of bioglass treatment, bone trabeculae surrounding the spaces taken up by implanted particles were more mature and interspersed with bone marrow. This was in agreement with Nelson et.al.,2004 (36), who found, after 30 days, bone trabeculae surrounding the spaces of the particles were thicker and more mature than in the previous stages, which showed signs of remodeling, as occurred on the surgical defect borders, and were interspersed with bone marrow. In some spaces, bone tissue formed in their excavations was observed in addition to thin bone septa. Other spaces presented delicate fibrilar material, sometimes with a reticular aspect. Vogel et al., 2001(37), found that Bioglass 45S5 was capable of accelerating bone consolidation on rabbit femur fracture, with the presence of an organized tissue in the implantation bed, 28 days after the surgery. Oonishi et al., 1997 showed full restoration of the implantation site filled with Bioglass 45S5 within 2 weeks. The same results were found by Wheleer et al., 2001.

In the present study, After 60 days of bioglass treatment, bone trabeculae surrounding the spaces of the particles were thicker and more mature than in the previous stages, which showed signs of remodeling, as occurred on the surgical defect borders, and were interspersed with bone marrow. This figure was in line with Nelson et al., 2004, who found, after 60 days, bone trabeculae surrounding the spaces taken up by particles were thicker, with a lamellar aspect, and were interspersed with bone marrow. Inside some of the spaces, a remaining structure from the implanted material was found integrated to the bone tissue, besides thin bone septa. These spaces showed a material with delicate fibrilar aspect, occasionally with a reticular appearance. There was bone growth inside granules in both materials, with indications of bone remodeling. The positive effects of Bioglass 45S5_ on the osteogenesis and on osteoblasts cell proliferation are well known. Moreover, bioactive glass has been used successfully in the clinic, primarily for oral and maxillofacial applications, with minimal load requirements, Wheeler et al., 2001.

Lastly, After 90 days, a picture of many bone trabeculae with well-developed bone cells, simulating normal was found in the present study, which was in agreement with Nelson et al., 2004, where his and our results histologically confirmed that the bioactive glass particles showed osteoconductive and osteointegration properties, as documented by the close contact between the material and the newly formed bone, as well as bone growth around them and inside the granules.

\section{Conclusion}

The prepared bioactive glass has demonstrated osteoconductive and osteopromotive abilities with faster proliferation of the new bone tissue. It can be used to help healing of surgically created defects both in dentistry as well as in orthopedics. This research will be a nucleus for more advanced and valuable researches, by preparation of new types of bioactive glasses, changing the animal model as well as uses in the field of dentistry and comparing with other methods like gene therapy and use of short laser waves in bone repair.

\section{References}

[1] Claes L, Willie B.: The enhancement of bone regeneration by ultrasound. Prog Biophys Mol Biol. 2007; 93:384-98.

[2] Gautier E.: Sommer guidelines for the clinical application of the LCP. Injury. 2003; 34:B63-76. (Review).

[3] Demers C, Hamdy CR, Corsi K, Chellat F, Tabrizian M, Yahia L.: Natural coral exoskeleton as a bone graft substitute: a review. Biomed Mater Eng 2002; 12:15-35.

[4] Müller ME, Allgöwer M, Schneider R, Willenegger H, eds. Manual of Internal Fixation, 3rd ed. New York: Springer, 1995.

[5] Wildemann B, Kadow-Romacker A, Haas NP, Schmidmaier G.: Quantification of various growth factors in different demineralized bone matrix preparations. J Biomed Mater Res, 2007; 81:437-42.

[6] Boyce T, Edwards J, Scarborough N.: Allograft bone. The influence of processing on safety and performance. Orthop Clin North Am 1999; 30:571-81.

[7] Ryan G, Pandit A, Apatsidis DP. :Fabrication methods of porous metals for use in orthopedic applications. Biomaterials 2006; 27:2651-70.

[8] Mahony O, Jones JR.: Porous bioactive nanostructured scaffolds for bone regeneration: a sol-gel solution. Nanomedicine (Lond) 2008; 3:233-45.

[9] Ohtsuki C, Kamitakahara M, Miyazaki T. Bioactive ceramicbased materials with designed reactivity for bone tissue regeneration. J R Soc Interface 2009; 6 (Suppl 3):S349-60.

[10] Yu NY, Schindeler A, Little DG, Ruys AJ. Biodegradable poly (alpha-hydroxy acid) polymer scaffolds for bone tissue engineering. J Biomed Mater Res B Appl Biomater 2010; 93:285-95.

[11] Bohner M.: Calcium orthophosphates in medicine: from ceramics to calcium phosphate cements. Injury 2000; 31, (Suppl 4):37-47.

[12] Jarcho M.: Calcium phosphate ceramics as hard tissue 1988, 523, 268-271.

[13] Daculsi G, Hartmann DJ, Heughebaert M, Hamel LLe: Bioceramics. J Submicrosc Cytol Pathol 1988, 20, 379- 384.

[14] Wilson J. and Low SB.: Bioactive ceramics for periodontal treatment. Comparative studies in the Patus monkey. J Appl Biomater 1992; 3:123-9.

[15] Low SB, King C, Krieger J.: An evaluation of bioactive ceramic in the treatment of periodontal osseous defects. Int $\mathrm{J}$ Periodontics Restorative Dent 1997; 17:359-67.M (Eds.). Operative Orthopedics. pp. 139-149, JB Lippincott,

[16] Turunen T, Peltola J, Helenius H, Yli-Urpo A, Happonen RP.: Bioactive glass and calcium carbonate granules as filler material around titanium and bioactive glass implants in the marrow space of the rabbit tibia. Clin Oral Impl Res 1997; 8:96-102. 
[17] Zamet JS, Darbar UR, Griffiths GS. : Particulate Bioglasses a grafting material in the treatment of periodontal intrabony defects. J Clin Periodontol 1997; 24:410-8. 3.

[18] Shapoff CA, Alexander DC, Clark AE.: Clinical use of a bioactive glass particulate in the treatment of human osseous defects. Compend Contin Educ Dent 1997; 18:352-63.Shors EC. Coralline bone graft substitutes. Orthop Clin the porosity and physical chemistry of calcium phosphate.

[19] Schepers E, De Clercq M, Ducheyn P.: Bioactive glass particulate material as filler for bone lesions. J Oral Rehabil, $1991 ; 18: 439-52$

[20] Oonishi H, Kushitani S, Yasukawa E, Iwaki H, Hench LL, and Wilson J, et al.: Particulate Bio Glass compared with hydroxyapatiteas a bone graft substitute. Clin Orthopaedics 1997; 334:316-25.

[21] Hench LL, Xynos ID, Polak JM.: Bioactive glasses for in situ tissue regeneration. J Biomater Sci Polym Ed. 2004; 15:54362.

[22] Hench LL, Paschal HA.: Direct chemical bond of bioactive glass ceramic materials to bone and muscle. J Biomed Mater Res 1970; 7:25-42.

[23] Thomas MV, Puleo DA, Al-Sabbagh M.: Bioactive glass three decades on. J Long Term Eff Med Implants. 2005; 15:585-97.

[24] Xynos ID, Edgar AJ, Buttery LD, and Hench LL, Polak JM.: Ionic products of bioactive glass dissolution increase proliferation of human osteoblasts and induce insulin-like growth factor II mRNA expression and protein synthesis. Biochem Biophys Res Commun. 2000; 276:461-5.

[25] Loty C, Sautier JM, Loty S, Hattar S, Asselin A, and Oboeuf $\mathrm{M}$, et al.: The biomimetics of bone: engineered glass-ceramics a paradigm for in vitro biomineralization studies. Connect Tissue Res.2002; 43:524-8.

[26] Gough JE, Notingher I, Hench LL.: Osteoblast attachment and mineralized nodule formation on rough and smooth $45 \mathrm{~S} 5$ bioactive glass monoliths. J Biomed Mater Res A. 2004; 68:640-50.

[27] Renata N. Granito Æ Daniel Araki Ribeiro Æ Ana Claudia M. Renno’ Æ Christian Ravagnani Æ Paulo S. Bossini $Æ$ Oscar Peitl-Filho $Æ$ Edgar D. Zanotto $Æ$ Nivaldo A. Parizotto $Æ$ Jorge Oishi.: Effects of biosilicate and bioglass $45 \mathrm{~S} 5$ on tibial bone consolidation on rats: a biomechanical and a histological study. J Mater Sci: Mater Med (2009) 20:2521-2526 DOI 10.1007/s10856-009-3824-z

[28] Ribeiro DA and Matsumoto MA.: Low-level laser therapy improves bone repair in rats treated with anti-inflammatory drugs. J Oral Rehabil. 2008; 35:925-33.

[29] Matsumoto MA, Ferino RV, and Monteleone GF, Ribeiro DA.: Low level laser therapy modulates cyclo-oxygenase-2 expression during bone repair in rats. Lasers Med Sci. 2009; 24:195-201.

[30] Hamadouche M, Sedel, L.: Ceramics in orthopedics. J Bone Joint Surg. (Br) 2000; 82-B (8):1095-9.

[31] Xin Liu, Mohamed N. Rahaman' and Qiang Fu: Bone regeneration in strong porous bioactive glass (13-93) scaffolds with an oriented microstructure implanted in rat calvarial defects. Acta Biomaterialia Volume 9, Issue 1, January 2013, Pages 4889-4898

[32] Maryam Seyedmajidi, Seyedmahmood Rabiee, Sina Haghanifar, Seyedkamal Seyedmajidi, Seyed Gholam ali Jorsaraei, Homayoun Alaghehmand Naghmeh Jamaatlu, and Ali Bijani: Histopathological, Histomorphometrical, and Radiographical Evaluation of Injectable Glass-CeramicChitosan Nanocomposite in Bone Reconstruction of Rat International Journal of Biomaterials Volume 2015 (2015), Article ID 719574, 8 pages

[33] Mikos AG, McIntire LV, Anderson JM, Babensee JE (1998). Host response to tissue engineered devices. Adv. Drug .Deliv. Rev., 33: 111-139.

[34] Wiley, Y.: Periodicals, Inc. J Biomed Mater Res Part B: Appl Biomater, 2001.

[35] Wheeler DL, Montfort MJ, Mc Loughlin SW. Differential healing Hydroxyapatite and 45S5 bioactive glass. J Biomed Mater Res. 2001; 55:603-12.

[36] Nelson Luiz de Macedo, Fábio da Silva Matuda, Luís Guilherme Scavonne de Macedo, Michel Borges Gonzalez, Suzana Martins Ouchi, Yasmin Rodarte Carvalho: Bone defect regeneration with bioactive glass implantation in rats. J Appl Oral Sci 2004; 12(2):137-43

[37] Vogell M, Voigt T, Gross U, Muk, C.: In vivo comparison of Particulate bioglass compared with hydroxyapatite as bioactive glass particles in rabbits. Biomaterials. 2001; 29:357-62. 